\title{
PENGGUNAAN METODE RELIABILITY-CENTERED MAINTENANCE UNTUK MENJAGA KEHANDALAN MATERIAL BELT CONVEYOR
}

\author{
Djoeli Satrijo \\ Departemen Teknik Mesin \\ Fakultas Teknik, Universitas Diponegoro \\ djoeli_satrijo@yahoo.com
}

\author{
Agus Suprihanto \\ Departemen Teknik Mesin \\ Fakultas Teknik, Universitas Diponegoro \\ agusm90@lecturer.undip.ac.id
}

\author{
Ojo Kurdi \\ Departemen Teknik Mesin, \\ Fakultas Teknik, \\ Universitas Diponegoro \\ ojokurdi@ft.undip.ac.id
}

\author{
Dwi Basuki Wibowo \\ Departemen Teknik Mesin, \\ Fakultas Teknik, \\ Universitas Diponegoro \\ dwibasukiwibowo@lecturer.undip.ac.id
}

\author{
Gunawan Dwi Haryadi \\ Departemen Teknik Mesin, \\ Fakultas Teknik, \\ Universitas Diponegoro \\ gunawandwiharyadi@lecturer.undip.ac.id
}

\author{
Yusuf Umardani \\ Departemen Teknik Mesin, \\ Fakultas Teknik, \\ Universitas Diponegoro \\ yusufumardani@lecturer.undip.ac.id
}

\author{
Khoiri Rozi \\ Departemen Teknik Mesin, \\ Fakultas Teknik, \\ Universitas Diponegoro \\ khoiri.rozi@yahoo.com
}

\author{
Muhammad Fakhri Aji Pratomo \\ Departemen Teknik Mesin, \\ Fakultas Teknik, \\ Universitas Diponegoro \\ ajikun0707@yahoo.com
}

\begin{abstract}
ABSTRAK
Alat transportasi berperan penting dalam mengangkut material konsentrat untuk diolah dalam pabrik smelter secara kontinyu. Peralatan tersebut dijaga agar selalu beroperasi tanpa ada kerusakan. Kerusakan alat dapat mengakibatkan terhentinya proses produksi. Oleh karena itu manajemen peralatan pabrik sangat penting, dengan melakukan maintenance secara berkala untuk menghindari kejadian yang tidak diinginkan. Permasalahan yang sering terjadi pada salah satu alat yaitu belt conveyor adalah adanya tumpahan material ketika beroperasi. Penelitian ini menerapkan metode Reliability Centered Maintenance untuk mengetahui solusi yang tepat atas permasalahan sehingga material belt conveyor memiliki kehandalan yang tinggi dan umur pakainya meningkat. Hasil penelitian menunjukkan bahwa failure mode yang terjadi pada belt conveyor merupakan kategori $\mathrm{C}$ dan memiliki persentase terbesar sehingga dampak kerugian ekonominya relatif kecil. Namun tetap demikian kemungkinan terjadinya outage pada plant tetap harus diperhatikan.
\end{abstract}

Kata kunci: alat transpirtasi, konveyor sabuk, perawatan, Reliability-Centered Maintenance, RCM.

\section{PENDAHULUAN}

Dalam pabrik industri terdapat sejumlah bangunan dan instalasi yang beroperasi dalam menghasilkan produk-produk yang akan dikirim untuk dapat diproses oleh masing-masing instalasi. Alat transportasi berperan penting dalam pengangkutan material konsentrat untuk diolah dalam pabrik smelter, oleh karena itu alat transportasi harus dijaga agar selalu beroperasi tanpa ada kerusakan yang dapat mengakibatkan terhentinya proses produksi. Kesalahan atau failure dalam proses transportasi konsentrat dapat mengakibatkan terhambatnya pabrik.

Operasi maintenance secara berkala dilakukan untuk menjaga peralatan pabrik beroperasi dengan baik dan menghindari kejadian yang tidak diinginkan. Di pabrik industri terdapat shutdown yang terjadwal secara mingguan, bulanan, dan biannual (dua tahun sekali) untuk menjaga operasi berjalan dengan baik.

Salah satu alat transportasi yang digunakan adalah belt conveyor. Alat ini dipakai untuk mengangkut konsentrat dengan meletakkan di atas belt yang akan bergerak sejauh jarak kedua ujung pulley dengan kecepatan konstan dan kontinyu. Conveyor merupakan alat transportasi sederhana namun efisien dalam operasi pabrik industri besar yang beroperasi 24 jam non-stop.

\section{DASAR TEORI DAN METODE}

Conveyor merupakan sistem perangkat atau rakitan mekanis yang mengangkut material dengan sedikit usaha. Meskipun ada banyak jenis sistem conveyor, sistem ini biasanya terdiri dari kerangka yang menopang rol, roda, atau sabuk, tempat material berpindah dari satu tempat ke tempat lain. Conveyor digerakkan oleh motor, gravitasi, atau secara manual. Sistem penanganan material ini tersedia dalam berbagai variasi untuk menyesuaikan dengan produk atau material yang perlu diangkut. 
Pemeliharaan atau maintenance merupakan aktivitas untuk merawat fasilitas dan peralatan agar senantiasa dalam keadaan siap pakai untuk mendukung produksi secara efektif dan efisien sesuai jadwal. Pemeliharaan membantu usaha mencapai operasi manufaktur dengan keandalan tinggi, memaksimalkan keluaran, serta meminimalkan biaya dan limbah. Hal ini memungkinkan perusahaan mendapatkan hasil maksimal dari aset yang ada dengan: a) mendefinisikan kembali peran pemeliharaan sebagai bagian dari program keandalan pabrik secara total, b) menyediakan infrastruktur dan proses, serta c) keterlibatan karyawan yang meningkatan hasil dan total harga pokok penjualan yang lebih rendah. Secara khusus akan membawa perubahan seperti menurunkan biaya unit produksi, mengurangi biaya pemeliharaan, meningkatkan stabilitas proses dan sejenisnya [1].

Maintenance secara umum terbagi menjadi beberapa jenis yaitu perawatan alat atau fasilitas yang dirawat, sebagai berikut:

1. Preventive Maintenance (PM).

Merupakan perawatan yang dilaksanakan secara periodic dengan rentang waktu yang sudah ditentukan, untuk mencegah timbulnya kerusakan pada fasilitas produksi dengan mengganti alat-alat yang sudah aus atau tidak layak lagi untuk digunakan pada belt conveyor.

2. Corrective Maintenance (CM).

Merupakan perawatan berdasarkan kondisi conveyor dengan adanya tanda cacat atau failure diluar prediksi. Preventive Maintenance yang terencana dengan baik akan meminimalkan terjadinya kegagalan mendadak pada conveyor.

3. Breakdown Maintenance.

Merupakan perawatan yang dilakukan ketika suatu alat atau fasilitas mengalami kerusakan yang mengakibatkan peralatan tersebut tidak dapat beroperasi normal atau berhenti total sehingga tidak bisa di operasikan sebelum diperbaiki. Breakdown maintenance harus dihindari karena dapat mengakibatkan kerugian operasional produksi mesin yang berujung tidak tercapainya output produksi pada plant availability. Apabila terjadi breakdown maintenance, maka jadwal outage maintenance dialihkan untuk meningkatkan efisiensi produksi.

4. Outage Maintenance.

Adalah pemeliharaan yang melakukan preventive maintenance secara keseluruhan dengan menghentikan operasi alat dalam waktu yang ditentukan. Kegiatan pemeliharaan pemadaman sangat penting untuk memperpanjang lifespan dan keandalan peralatan pabrik seperti conveyor.

\section{Reliability-Centered Maintenance (RCM)}

Maintenance berasal dari kata "to maintain" yang memiliki arti "merawat" dan setara dengan kata "to repair" yang berarti "memperbaiki".
Maintenance adalah tindakan merawat atau memperbaiki suatu komponen agar dapat digunakan kembali dan berumur panjang. Pekerjaan ini dilakukan secara berurutan untuk menjaga atau memperbaiki fasilitas yang ada sehingga sesuai dengan standar [6].

Reliability Centered Maintenance (RCM) merupakan metode analisis pemeliharaan yang digunakan untuk memperbaiki sistem pemeliharaan dengan fokus untuk meningkatkan kehandalan. Pendekatan pemeliharaan menggabungkan praktek dan strategi PM dan CM untuk memaksimalkan umur (life time) dan fungsi asset, sistem atau equipment dengan biaya minimal. Konsep dari RCM adalah bahwa semua komponen memiliki batas umur. Jumlah kegagalan yang umum terjadi mengikuti kurva bak mandi (bathtub curve). Kurva ini menggambarkan umur pakai suata alat, dimana semakin lama pemakaian, semakin tinggi biaya perawatannya.

Metode RCM sudah lama dipakai di berbagai sektor industri. Pada umumnya perangkat lunak komputer (software) untuk RCM merupakan perangkat lunak berlisensi dan hanya bisa bekerja untuk satu komputer saja. Pengembangan RCM berbasis web saat ini merupakan sistem informasi yang mendukung perawatan dan dapat bekerja dalam jaringan intranet atau internet. Perangkat lunak ini berlisensi Free Open Source Software (FOSS) atau GPL (General Public License), memungkinkan pengguna untuk melakukan duplikasi serta mengubah jika diperlukan pada perangkat lunak tersebut (free software) [2].

RCM memiliki metode tujuh langkah. Metode ini menjamin dokumentasi yang mencatat dengan tepat bagaimana tugas pemeliharaan dipilih dan mengapa ini adalah pilihan terbaik di antara sejumlah alternatif yang bersaing. Tujuh langkah ini meliputi [3]:

1. Pemilihan Sistem dan Pengumpulan Data.

Pemilihan sistem dapat didasarkan pada beberapa aspek kriteria seperti sistem dengan jumlah corrective maintenance, biaya pengeluaran dan jumlah preventive maintenance yang tinggi atau sistem yang paling berkontribusi terhadap terjadinya pemberhentian operasi pabrik [3].

2. Definisi Batasan Sistem.

Identifikasi suatu sistem bergantung pada berbagai factor yaitu kompleksitas pabrik, peraturan dan batasan pemerintah, praktik industri lokal atau unik, struktur keuangan perusahaan, dan lain-lain. Meski definisi dan batasan sistem bruto telah diidentifikasi untuk kasus-kasus tertentu dan dapat digunakan untuk efek yang baik di langkah pertama namun tidak cukup untuk analisis lebih lanjut. Oleh karenanya identifikasi batas yang terperinci dan tepat, sangat penting [3].

3. Deskripsi Sistem dan Diagram Blok Fungsional. Deskripsi sistem dan diagram blok merupakan representasi dari fungsi-fungsi utama sistem lewat 
simbol blok. Simbol ini berisi fungsi-fungsi setiap sub sistem yang menyusun sistem tersebut [3]. 4. System Function dan Kegagalan Fungsional. Fungsi merupakan kinerja yang diharapkan oleh suatu sistem untuk dapat beroperasi. Functional failure (FF) merupakan ketidakmampuan suatu komponen atau sistem dalam memenuhi standar prestasi yang diharapkan [3].

5. Failure Mode and Effective Analysis (FMEA) FMEA disusun berdasarkan fungsi komponen dan laporan perawatan sehingga dapat ditentukan penyebab kegagalan fungsi serta dampak yang diakibatkan dari kegagalan tersebut. Penilaian dilakukan dengan tiga variabel yaitu severity, occurence dan detection. Persamaan untuk menghitung risk priority number (RPN) adalah sebagai berikut [4]:

$$
\mathrm{RPN}=\mathrm{S} \times \mathrm{O} \times \mathrm{D}
$$

dimana $\mathrm{S}$ adalah severity, $\mathrm{O}$ adalah occurence, dan $\mathrm{D}$ adalah detection. Variabel S merupakan penilaian tingkat keseriusan suatu efek atau akibat dari potensi kegagalan pada proses yang dianalisis [7]. Dampak dinyatakan dengan rating mulai dari skala 1 sampai 10. Skala 1 merupakan dampak paling ringan sedangkan 10 adalah dampak terburuk [4]. Detail rating severity tertera pada Tabel 1 berikut:

Tabel 1. Skala tingkat kerusakan (Severity)

\begin{tabular}{|c|c|c|}
\hline Level & Severity & Deskripsi \\
\hline 1 & $\begin{array}{l}\text { Tidak ada } \\
\text { efek }\end{array}$ & tidak ada efek \\
\hline 2 & $\begin{array}{l}\text { Sangat } \\
\text { kecil }\end{array}$ & $\begin{array}{l}\text { efek yang diabaikan pada } \\
\text { kinerja sistem }\end{array}$ \\
\hline 3 & kecil & $\begin{array}{l}\text { sedikit berpengaruh pada } \\
\text { kinerja sistem }\end{array}$ \\
\hline 4 & $\begin{array}{l}\text { sangat } \\
\text { rendah }\end{array}$ & $\begin{array}{l}\text { efek yang kecil pada performa } \\
\text { sistem }\end{array}$ \\
\hline 5 & rendah & $\begin{array}{l}\text { mengalami penurunan kinerja } \\
\text { secara bertahap }\end{array}$ \\
\hline 6 & sedang & $\begin{array}{l}\text { sistem yang beroperasi } \\
\text { mengalami penurunan performa } \\
\text { yang mempengaruhi output }\end{array}$ \\
\hline 7 & tinggi & $\begin{array}{l}\text { sistem beroperasi namun tidak } \\
\text { dapat dijalan secara penuh }\end{array}$ \\
\hline 8 & $\begin{array}{l}\text { sangat } \\
\text { tinggi }\end{array}$ & sistem tidak beroperasi \\
\hline 9 & $\begin{array}{c}\text { berbahaya } \\
\text { dengan } \\
\text { peringatan }\end{array}$ & $\begin{array}{c}\text { kegagalan sistem yang } \\
\text { menghasilkan efek berbahaya }\end{array}$ \\
\hline 10 & $\begin{array}{l}\text { berbahaya } \\
\text { tanpa } \\
\text { peringatan }\end{array}$ & $\begin{array}{c}\text { kegagalan sistem yang } \\
\text { menghasilkan efek sangat } \\
\text { berbahaya }\end{array}$ \\
\hline
\end{tabular}

Occurence merupakan rating yang mengacu kepada frekuensi terjadinya cacat pada produk. Frekuensi kegagalan menunjukkan adanya ulangan suatu masalah yang terjadi akibat potential cause [4]. Nilai yang menjabarkan penentuan occurence rating tertera pada Tabel 2 berikut:
Tabel 2 Skala frekuensi kerusakan (Occurence)

\begin{tabular}{|c|c|c|}
\hline Level & Occurrence & Intensitas Kerusakan \\
\hline 1 & $\begin{array}{l}\text { Tidak ada } \\
\text { efek }\end{array}$ & Hampir tidak ada kegagalan \\
\hline 2 & Rendah & Sangat kecil terjadi kegagalan \\
\hline 3 & & \\
\hline 4 & Sedang & Jarang terjadi kegagalan \\
\hline 5 & & \\
\hline 6 & & \\
\hline 7 & Tinggi & Kegagalan yang berulang \\
\hline 8 & & \\
\hline 9 & Sangat & Sering gagal \\
\hline 10 & Tinggi & \\
\hline
\end{tabular}

Detection adalah sebuah kontrol proses yang mendeteksi secara spesifik akar penyebab kegagalan [4]. Pengukuran untuk pengendalian kegagalan dilakukan dengan skala pada Tabel 3 .

Tabel 3 Skala Tingkat Deteksi (Detection)

\begin{tabular}{|c|c|c|}
\hline Level & $\begin{array}{l}\text { Tingkat } \\
\text { Deteksi }\end{array}$ & Kriteria \\
\hline 1 & $\begin{array}{l}\text { Hampir } \\
\text { Pasti }\end{array}$ & $\begin{array}{l}\text { Pemeriksaan selalu mendeteksi } \\
\text { penyebab potensial atau mekanisme } \\
\text { dan mode kegagalan }\end{array}$ \\
\hline 2 & $\begin{array}{l}\text { Sangat } \\
\text { Tinggi }\end{array}$ & $\begin{array}{l}\text { Pemeriksaan memiliki kemungkinan } \\
\text { sangat tinggi untuk mendeteksi } \\
\text { penyebab potensial atau mekanisme } \\
\text { dan mode kegagalan }\end{array}$ \\
\hline 3 & Tinggi & $\begin{array}{l}\text { Pemeriksaan memiliki kemungkinan } \\
\text { tinggi untuk mendeteksi penyebab } \\
\text { potensial atau mekanisme dan mode } \\
\text { kegagalan }\end{array}$ \\
\hline 4 & $\begin{array}{l}\text { Menengah } \\
\text { Keatas }\end{array}$ & $\begin{array}{l}\text { Pemeriksaan memiliki kemungkinan } \\
\text { moderately high untuk mendeteksi } \\
\text { penyebab potensial atau mekanisme } \\
\text { dan mode kegagalan }\end{array}$ \\
\hline 5 & Sedang & $\begin{array}{l}\text { Pemeriksaan memiliki kemungkinan } \\
\text { moderate untuk mendeteksi } \\
\text { penyebab potensial atau mekanisme } \\
\text { dan mode kegagalan }\end{array}$ \\
\hline 6 & Rendah & $\begin{array}{l}\text { Pemeriksaan memiliki kemungkinan } \\
\text { rendah untuk mendeteksi penyebab } \\
\text { potensial atau mekanisme dan mode } \\
\text { kegagalan }\end{array}$ \\
\hline 7 & $\begin{array}{l}\text { Sangat } \\
\text { Rendah }\end{array}$ & $\begin{array}{l}\text { Pemeriksaan memiliki kemungkinan } \\
\text { sangat rendah untuk mendeteksi } \\
\text { penyebab potensial atau mekanisme } \\
\text { dan mode kegagalan }\end{array}$ \\
\hline 8 & Kecil & $\begin{array}{l}\text { Pemeriksaan memiliki kemungkinan } \\
\text { kecil untuk mendeteksi penyebab } \\
\text { potensial atau mekanisme dan mode } \\
\text { kegagalan }\end{array}$ \\
\hline 9 & $\begin{array}{l}\text { Sangat } \\
\text { Kecil }\end{array}$ & $\begin{array}{l}\text { Pemeriksaan memiliki kemungkinan } \\
\text { sangat kecil untuk mendeteksi } \\
\text { penyebab potensial atau mekanisme } \\
\text { dan mode kegagalan }\end{array}$ \\
\hline 10 & $\begin{array}{l}\text { Tidak } \\
\text { Pasti }\end{array}$ & $\begin{array}{l}\text { Pemeriksaan selalu tidak mampu } \\
\text { mendeteksi penyebab potensial atau } \\
\text { mekanisme dan mode kegagalan }\end{array}$ \\
\hline
\end{tabular}

6. Logic or Decision Tree Analysis (LTA)

LTA bertujuan untuk memprioritaskan lebih lanjut sumber daya yang akan digunakan pada setiap 
mode kegagalan. Hal ini dilakukan karena dampak setiap mode kegagalan terhadap keseluruhan plant tidak sama. Skema logis apapun dapat diadopsi untuk melakukan pemeringkatan ini. RCM memproses logika tiga pertanyaan sederhana dan intuitif dari struktur keputusan sehingga memungkinkan pengguna, dengan sedikit usaha, untuk menempatkan setiap mode kegagalan ke dalam salah satu dari empat kategori. Setiap pertanyaan dijawab ya atau tidak. Setiap kategori yang dikenal sebagai bin membentuk pemisahan alami dari item dengan kepentingan masing-masing. Pada skema ini terdapat tiga kategori dan satu katogeri D yang merupakan hidden failure, menjelaskan apakah operator sadar apakah kegagalan ini diketahui saat bertugas? Jika tidak maka dilanjutkan ke kategori A yang merupakan masalah keamanan atau safety issue, menjelaskan apakah kegagalan tersebut berhubungan dengan keselamatan pekerja? Selanjutnya diakhiri dengan kategori B dan C. Kategori B berhubungan dengan terjadinya outage issue atau pemadaman pabrik. Kategori C merupakan masalah minor dan dengan dampak kerugian ekonomi yang relatif kecil.

Mekanisme ini membuat suatu alat masuk dalam kategori A, B, C, D/A, D/B atau D/C. Untuk skema prioritas, $\mathrm{A}$ dan $\mathrm{B}$ memiliki prioritas lebih tinggi daripada $\mathrm{C}$ dalam hal alokasi sumber daya yang langka, selain itu A diberi prioritas lebih tinggi dari B [3].

\section{Pemilihan Tindakan}

Pemilihan tindakan adalah langkah terakhir pada metode analisa menggunakan RCM. Tiap mode kerusakan dibuat daftar tindakan yang mungkin untuk dilakukan dan selanjutnya memilih tindakan yang paling efektif. Diagram alir pemilihan tindakan tertera pada [5]. Dalam pelaksanaannya pemilihan tindakan dapat dilakukan dengan empat cara, yaitu:

a. Time Directed (TD)

Tindakan pencegahan langsung terhadap sumber kerusakan peralatan berdasarkan waktu atau umur komponen.

b. Condition Directed (TD)

Tindakan mendeteksi kerusakan dengan memeriksa alat. Apabila ditemukan gejala-gejala kerusakan maka dilanjutkan dengan perbaikan atau penggantian komponen.

c. Failure Finding (FF)

Tindakan untuk menemukan kerusakan peralatan yang tersembunyi dengan pemeriksaan berkala.

d. Run to Failure (RTF)

Suatu tindakan menggunakan peralatan sampai rusak, karena tidak ada tindakan ekonomis lain yang dapat dilakukan untuk mencegah kerusakan.

\section{ANALISIS DAN PEMBAHASAN}

Hasil dari analisis menunjukkan bahwa belt conveyor memiliki fungsi sistem dan kegagalan fungsional sebagaimana ditunjukkan pada Tabel 4 berikut.

Tabel 4 System function and functional failure

\begin{tabular}{|l|l|l|}
\hline Nama Alat & Fungsi & Kegagalan Fungsi \\
\hline Wet Conc Belt & Alat & $\bullet$ Material Spillage \\
Conveyor & transportasi & - Component \\
& konsentrat & Damage \\
& tembaga & $\begin{array}{l}\text { - Belt Damage } \\
\text { - Structure Damage }\end{array}$ \\
& & \multicolumn{2}{|l}{} \\
\end{tabular}

1. Failure Mode and Effect Analysis (FMEA) Tabel 5 menunjukkan hasil perhitungan Failure Mode and Effect Analysis.

Tabel 5 Failure Mode and Effect Analysis

\begin{tabular}{|c|c|c|c|c|c|c|c|c|}
\hline Name & $\begin{array}{l}\text { Potential Failure } \\
\text { Mode }\end{array}$ & $\begin{array}{l}\text { Potential Effect(s) } \\
\text { of Failure }\end{array}$ & $\vec{\omega}$ & $\begin{array}{l}\text { Potential Cause(s) / } \\
\text { Mechanism(s) of Failure }\end{array}$ & $\vdots$ & 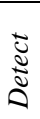 & Z & $\grave{z}_{a}^{\circ}$ \\
\hline \multirow{4}{*}{ 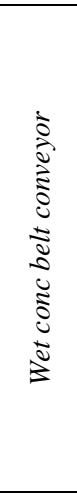 } & $\begin{array}{l}\text { Material spillage / } \\
\text { carry back }\end{array}$ & Material spillage & 6 & Rule Zero, idlers miring & 7 & 2 & 84 & 11,4 \\
\hline & $\begin{array}{l}\text { Belt Loading Not } \\
\text { Central (vibrating } \\
\text { Feeder) }\end{array}$ & Material spillage & 4 & Gravity & 5 & 2 & 40 & 5,44 \\
\hline & Extreme weather & Material spillage & 6 & $\begin{array}{l}\text { Strong wind, rain causing } \\
\text { slippage, etc }\end{array}$ & 6 & 5 & 180 & 24,5 \\
\hline & $\begin{array}{l}\text { Not enough belt } \\
\text { tension }\end{array}$ & Belt damage & 5 & $\begin{array}{l}\text { Belt memuai, built up tension, } \\
\text { material aus }\end{array}$ & 3 & 6 & 90 & 12,2 \\
\hline & & & & & Tot & & 735 & 100 \\
\hline
\end{tabular}


2. Logic or Decision Tree Analysis (LTA)

Tabel 6 menunjukkan hasil analisis LTA yaitu tahapan setelah perhitungan FMEA.

Tabel 6. Logic or Decision Tree Analysis.

\begin{tabular}{|c|c|c|c|c|c|}
\hline \multirow[t]{2}{*}{ Nama } & \multirow{2}{*}{$\begin{array}{l}\text { Failure } \\
\text { Mode }\end{array}$} & \multicolumn{4}{|c|}{ Failure Effect } \\
\hline & & Evident & Safety & Outage & Category \\
\hline \multirow{7}{*}{ 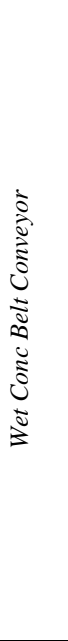 } & $\begin{array}{l}\text { Material } \\
\text { Spillage } \\
\text { / Carry } \\
\text { Back }\end{array}$ & $\mathrm{Y}$ & $\mathrm{Y}$ & $\mathrm{N}$ & $\mathrm{C}$ \\
\hline & $\begin{array}{l}\text { Extreme } \\
\text { Weather }\end{array}$ & $\mathrm{N}$ & $\mathrm{Y}$ & $\mathrm{N}$ & $\mathrm{D} / \mathrm{C}$ \\
\hline & $\begin{array}{l}\text { Not } \\
\text { Enough } \\
\text { Belt } \\
\text { Tension }\end{array}$ & $\mathrm{Y}$ & $\mathrm{Y}$ & $\mathrm{N}$ & $\mathrm{C}$ \\
\hline & $\begin{array}{l}\text { Roller } \\
\text { Seized or } \\
\text { Uneven }\end{array}$ & $\mathrm{Y}$ & $\bar{Y}$ & $\mathrm{Y}$ & B \\
\hline & $\begin{array}{l}\text { Belt } \\
\text { Chamber }\end{array}$ & $\mathrm{Y}$ & $\mathrm{Y}$ & $\mathrm{N}$ & $\mathrm{C}$ \\
\hline & $\begin{array}{l}\text { Wear on } \\
\text { Parts }\end{array}$ & $\mathrm{Y}$ & $\mathrm{Y}$ & $\mathrm{Y}$ & B \\
\hline & $\begin{array}{l}\text { Belt } \\
\text { Loading } \\
\text { Not } \\
\text { Central }\end{array}$ & $\mathrm{N}$ & $\mathrm{Y}$ & $\mathrm{N}$ & $\mathrm{D} / \mathrm{C}$ \\
\hline
\end{tabular}

Tabel 6 tersebut berisi data hasil analisis mengenai keseluruhan bagian belt conveyor. Dapat disimpulkan bahwa failure mode kategori A sebesar 0\%, kategori B 28,6\%, kategori C 42,8\%, dan kategori D 28,6\%.

3. Pemilihan Tindakan

Pemilihan tindakan kerusakan (TD, CD, FF dan RTF) ditunjukkan pada Tabel 7.

Tabel 7 Pemilihan Tindakan Kerusakan

\begin{tabular}{|c|c|c|c|}
\hline $\begin{array}{l}\text { Nama } \\
\text { Alat }\end{array}$ & $\begin{array}{l}\text { Failure } \\
\text { mode }\end{array}$ & $\begin{array}{c}\text { Usulan } \\
\text { tindakan }\end{array}$ & Saran \\
\hline \multirow{7}{*}{ 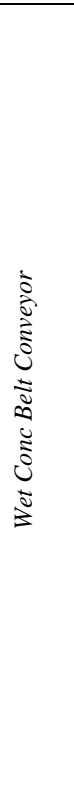 } & $\begin{array}{l}\text { Material } \\
\text { Spillage / } \\
\text { Carry } \\
\text { Back }\end{array}$ & $\mathrm{CD}$ & $\begin{array}{l}\text { Adjustment pada } \\
\text { Scraper agar tidak ada } \\
\text { material yang } \\
\text { menempel saat carry } \\
\text { back. }\end{array}$ \\
\hline & $\begin{array}{l}\text { Extreme } \\
\text { Weather }\end{array}$ & $\mathrm{CD}$ & $\begin{array}{l}\text { Pemberian cover pada } \\
\text { belt conveyor untuk } \\
\text { mejaga dari angin dan } \\
\text { hujan. }\end{array}$ \\
\hline & $\begin{array}{l}\text { Not } \\
\text { Enough } \\
\text { Belt } \\
\text { Tension } \\
\end{array}$ & TD & $\begin{array}{l}\text { Pemeriksaan berkala } \\
\text { pada belt tension. }\end{array}$ \\
\hline & $\begin{array}{l}\text { Roller } \\
\text { Seized or } \\
\text { Uneven }\end{array}$ & TD & $\begin{array}{l}\text { Pemeriksaan berkala } \\
\text { pada roller. }\end{array}$ \\
\hline & $\begin{array}{l}\text { Belt } \\
\text { Chamber }\end{array}$ & $\mathrm{FF}$ & $\begin{array}{l}\text { Pemeriksaan berkala } \\
\text { kualitas dan storage } \\
\text { management yang } \\
\text { sesuai. }\end{array}$ \\
\hline & $\begin{array}{l}\text { Wear on } \\
\text { Parts }\end{array}$ & TD & $\begin{array}{l}\text { Pemeriksaan berkala } \\
\text { pada parts conveyor. }\end{array}$ \\
\hline & $\begin{array}{l}\text { Belt } \\
\text { Loading } \\
\text { Not } \\
\text { Central }\end{array}$ & FF & $\begin{array}{l}\text { Pemeriksaan berkala } \\
\text { visual kondisi feeder. }\end{array}$ \\
\hline
\end{tabular}

\section{KESIMPULAN}

Kesimpulan dari penelitian ini adalah:

1. Masalah utama pada belt conveyor yaitu material jatuh dari belt saat diangkut merupakan kegagalan minor karena nilai risk priority number (RPN) rendah yaitu $11,4 \%$.

2. Data Failure Mode and Effective Analysis (FMEA) menunjukkan tujuh penyebab potensi kegagalan. Potensi kegagalan tertinggi terlihat dari persentase RPN yaitu 39,2\%. Hal ini mengindikasikan salah satu part yang aus yaitu bearing karena kontaminasi lingkungan.

3. Logic Tree Analysis (LTA) menunjukkan adanya empat kategori failure mode, dengan kategori A, B, C dan D masing - masing sebesar $0 \%, 28,6 \%, 42,8 \%$, dan 28,6\%.

4. Failure mode yang terjadi pada belt conveyor merupakan kategori C karena memiliki persentase terbesar dengan dampak kerugian ekonomi yang relatif kecil. Kemungkinan terjadinya outage pada plant tetap harus diperhatikan.

5. Untuk mencegah terjadinya mode kegagalan kategori $\mathrm{C}$, perlu dilakukan perawatan rutin (PM) dan inspeksi secara berkala.

6. Metode perawatan RCM akan meningkatkan kehandalan material belt conveyor dengan berkurangnya keausan pada komponen conveyor tersebut.

\section{REFERENSI}

1. Keith, M. R., Higgins, L. R., Wikoff, D. J., 2008, Maintenance Engineering Handbook 7th Edition. Mc-GrawHill Co., Inc.

2. Tahril, M. A., Suprawhardana, M. S., Pudji, T. P., 2010, "Penerapan Metode Reliability Centered Maintenance (RCM) Berbasis Web pada Sistem Pendingin Primer di Reaktor Serba Guna GA", Siwabessy, JFN 4 (1).

3. Siddiqui, A. W. and Ben-Daiya, M., 2009, Reliability Centered Maintenance.

4. McDermott, R. E., Mikulak, R. J., Beauregard, M.R., 2009, The Basic of FMEA $2^{\text {nd }}$ Ed., Taylor and Francis Group, New York.

5. Moubray, J., 1997, Reliability-Centered Maintenance, Industrial Press Inc.

6. Teoh, P. C., Case, K., 2005, "An Evaluation of Failure Modes and Effect Analysis Generation Method for Conceptual Design", Int. J. Computer Integrated Manufacturing 18 (4), pp. 279-293. 